DOI: $10.22616 /$ REEP.2020.042

\title{
Starting and Maintaining Smoking: A Qualitative Study of Tobacco Use in High School Students
}

\author{
Aija Zobena ${ }^{1}$ Dr.soc.; Anete Skrastina ${ }^{2}$ Mg.sc.pol. \\ University of Latvia, Latvia \\ aija.zobena@lu.lvin; anete.skrastina@lu.lv ${ }^{2}$
}

\begin{abstract}
Despite the detrimental impact of smoking to health, its prevalence remains high. Most students who smoke start to do so regularly around the age of 16-18. Although the proportion of smokers in Latvia is decreasing, the share of electronic cigarette users among young people is growing prematurely, which indicates a change of habits among young people. The aim of the study is to investigate the motives for starting smoking, the factors that contribute to smoking initiation and how high school students become "regular smokers" from "trying" tobacco products. In February 2019, two focus group discussions were organized to obtain information on young people's smoking experience. In each of them, high school students (aged over 18) and students took part. The participants of the focus group discussion were chosen by the "snowball" method. Social factors and the social and psychological characteristics of adolescents have a major impact on the transition from the first cigarette smoked by peers to regular smoking. According to the study, so-called social smoking is prevalent among young people, where smoking is one of the elements of starting and maintaining a relationship, and the smoker himself feels that he is not addicted to smoking and does not think it is necessary to quit.
\end{abstract}

Keywords: adolescent smoking, social smoking, smoking behaviour, electronic cigarettes, heated tobacco.

\section{Introduction}

Studies of smoking habits have concluded that smoking is not only an addiction to physical manifestations (overwhelming need to smoke, difficulty concentrating, insomnia, weight gain after quitting smoking), it is also associated with maintaining social bonds and social rituals (peculiar initiation rituals for young people, smoking situations) as well as emotional and physical enjoyment (Bevan, 2016).A quantitative study comparing smokers and non-smokers found that the impact of the social context on smoking initiation and the transition to regular smoking is significant. Smokers are more likely to live with smokers, have more friends who smoke, partners with smokers, while non-smokers have less contact with smokers (Johnson et al., 2019).

In Latvia, like in many other new EU Member States the lack of data is the main cause, which prevents comprehensive and objective analysis of the burden smoking causes to society (Kokarēviča, 2015). A new and relatively little studied phenomenon is the use of electronic cigarettes and heated tobacco. From a health point of view, most authors recommend to apply caution in promoting these products (Egbe, Parry, Myers, 2019), claiming that these tobacco products, such as electronic cigarettes (e-cigarettes), are more attractive to young people and contribute or may contribute to nicotine addiction in children / adolescents, to accustom them to the smoking ritual.

However, studies have not directly confirmed this claim Thus, according to a survey conducted in Finland in 2014, only $2 \%$ of all respondents $(\mathrm{N}=7000,3485$ respondents) smoke e-cigarettes, while $12 \%$ have ever, even once, tried them. Share of respondents with lower levels of education and social status, unemployed is higher among e-cigarette smokers than among non-smokers. On the other hand, there are more young people and students among those who have just tried e-cigarettes but do not smoke at present (Ruokolainen, Ollila, Karjalainen, 2017). A study from the UK also shows that while young people's experimentation with e-cigarettes has increased in recent years, regular use is still low. Only $1.7 \%$ of smokers under the age of 18 smoke e-cigarettes weekly or more frequently. Among young people who have never smoked before, only $0.2 \%$ regularly use e-cigarettes. Although more and more young people are experimenting with e-cigarettes, the decisive fact is that regular use is still low and particularly low among those who have never smoked (Regular e-cigarette use..., 2019), suggesting that young people rarely start smoking directly with e-cigarettes. There is currently insufficient evidence that smoke free products encourage young people to start smoking. 
Research on the subculture of e-cigarette smokers reveals how e-cigarette users socialize with each other, discuss the advantages or disadvantages of various accessories. However, the prevailing view is that these products are intended for those who cannot quit and are aware of e-cigarettes as a "healthier" tobacco use, a way to reduce passive smoking. So, very often, e-cigarette users are well aware of the harms of smoking and look for ways to avoid at least some of the negative side effects of tobacco use unpleasant odours, yellow stains on their fingers, passive smoking - and also consider e-cigarettes as a way to quit or at least reduce smoking (Bevan, 2016).

Both smokers and non-smokers alike are relatively well aware of the harmful health effects of smoking, and smokers have no illusions that smoking can be compatible with a healthy lifestyle (Fitz, Kaufman, Moore, 2015), and thus the ability to maintain social and pleasure functions, while limiting the harmful effects of cigarette smoke on both the smoker and those around him. Nicotine-containing tablets, patches are discreet in use, while e-cigarettes, heated tobacco use allows the maintenance of social rituals associated with tobacco use as well as the enjoyment of taste and the use of various accessories, making the smokeless tobacco products less harmful to the environment, while perceiving it as a peculiar substitute for these social and hedonic aspects of tobacco use (Bevan, 2016).

As part of the Global Youth Tobacco Surveillance System since 2002 surveys are conducted regularly in Latvia to assess the dynamics of smoking among young people. Although the data of the Centre for Disease Prevention and Control of Latvia show that the proportion of young people smoking in Latvia has decreased, the share of smoking in Latvia is still very high. The analysis of the study data shows that the proportion of regular smokers among 15 -year-oldsdecreased by $12 \%$ over four years and returned close to the 1995 survey when $17 \%$ of the surveyed 15-year-olds smoked regularly (Gavare, Lepiksone, 2017). Quantitative data analysis does not provide information on subjective smoking experience and habits, motives initiating or cessation of smoking.

Smoking cessation is much more difficult than not to initiate smoking at all. Interventions targeted at teens, including those that address social and environmental influences, are clearly still needed to prevent escalation of smoking as they move toward young adulthood (Lenk, Erickson, Forster, 2018) The aim of the study is to investigate the motives for starting smoking, the factors that contribute to smoking initiation and how high school students become "regular smokers" from "trying" tobacco products.

\section{Methodology}

The main method of data acquisition used in the study is focus group discussion. In February 2019, two focus group discussions were conducted to obtain information on smoking experience among young people, tobacco use patterns and attitudes toward alternative tobacco products. It was planned to invite 6-8 participants (smokers) - adult pupils and students - to the discussion for about one and a half hours. The participants of the discussion were warned in advance and agreed to the recording of the discussion in an audio recording. At the beginning of the discussion it was made clear that the information obtained would be anonymized and used only in aggregate form. The discussion took place in a free, relaxed atmosphere.

The participants of the focus group discussion were selected using the "snowball" method. Involvement of participants of age under 18 would be difficult because their participation would require parental authorization, but at this age many teenagers from parents hide the fact that they smoke. It would also be difficult to organize such a discussion at school, because the attitude of teachers and classmates non-smokers to smokers often is negative.

The focus group discussion included questions on how and why young people initiate smoking, their smoking experience and habits, their choice of tobacco products, how they are perceived by others (friends, classmates, family members, teachers), attitudes towards smoking restrictions in public environment and cessation of smoking, treatment of tobacco products alternative to traditional tobacco smoking (e-cigarettes, heated tobacco). The focus group of students was organized because the beginning of studies often involves leaving parents' homes and starting independent living in dormitories or rented accommodation, forming a new circle of acquaintances, starting work, planning independent spending of money. Open smoking is often perceived as one of the hallmarks of independent living. Participants of the student focus group discussion are described in Table 1. 
Participants of the student focus group discussion

\begin{tabular}{lcll}
\hline Participant & $\begin{array}{c}\text { Smoking history } \\
\text { (years) }\end{array}$ & $\begin{array}{c}\text { Smoking } \\
\text { intensity }\end{array}$ & \multicolumn{1}{c}{ Tobacco products used } \\
\hline Female student 1 & $5-6$ & regularly & Cigarettes, heated tobacco \\
Female student 2 & $5-6$ & irregularly & Cigarettes, heated tobacco \\
Male student 1 & $4-5$ & regularly & Cigarettes, e-cigarettes, heated tobacco \\
Male student 2 & 4 & regularly & Cigarettes, e-cigarettes \\
\hline
\end{tabular}

The high school last year students are 18-19 years old, have recently reached adulthood and thus have the opportunity to legally buy tobacco products. Teachers have a negative attitude towards smoking and smoking is prohibited in and around the school. Participants of the high school student focus group discussion are described in Table 2.

Table 2

Participants of the high school student focus group discussion

\begin{tabular}{|c|c|c|c|}
\hline Participant & $\begin{array}{c}\text { Smoking } \\
\text { history (years) }\end{array}$ & Smoking intensity & Tobacco products used \\
\hline Female high school student 1 & 2 & regularly & $\begin{array}{l}\text { Cigarettes, rolling tobacco, } \\
\text { hookah and e-cigarettes }\end{array}$ \\
\hline Female high school student 2 & 2,5 & irregularly & $\begin{array}{l}\text { Cigarettes, rolling tobacco, } \\
\text { hookah and heated tobacco }\end{array}$ \\
\hline Male high school student 1 & 1 & regularly & $\begin{array}{l}\text { Cigarettes, e-cigarettes, } \\
\text { hookah, heated tobacco }\end{array}$ \\
\hline Male high school student 2 & 1,5 & regularly & $\begin{array}{l}\text { Cigarettes, e-cigarettes, } \\
\text { hookah }\end{array}$ \\
\hline Male high school student 3 & 1,5 & $\begin{array}{l}\text { quit smoking two weeks } \\
\text { ago, then smoked } \\
\text { regularly }\end{array}$ & $\begin{array}{l}\text { Cigarettes, heated tobacco, e- } \\
\text { cigarettes, hookah, cigars, } \\
\text { pipe tobacco }\end{array}$ \\
\hline
\end{tabular}

Young people are a very heterogeneous social group. Compared to other peers, Riga high school students and students are generally better financially aware, more aware of the negative effects of smoking, motivated to pursue a professional career, to lead a healthy lifestyle. Smoking habits of young people from less favourable social backgrounds with lower education, low-skilled, unemployed may differ significantly (Johnson et al., 2019) from those of the participants in these focus group discussions.

\section{Results and Discussion}

The focus group participants were selected by the "snowball" method, addressing students of the University of Latvia and Jāzeps Vìtols Latvia Academy of Music, and high school students from Riga (age $18+)$. Public attitudes to smoking are ambiguous, smoking in public places is limited, and information on the harmful effects of nicotine-containing products is widely available, which may have failed to reach the intended number of participants. Some invited participants who initially agreed to attend did not appear.

The discussion was attended by pupils from the gymnasium in the centre of Riga, where admission is by competition. During the discussion it became clear that most of their classmates did not smoke. The situation may be different in Riga district schools. Although some participants of the focus group discussion work, their income is irregular, cigarettes are mainly bought for the pocket money given by their parents.

Participants of the discussion had different smoking history and intensity; they prefer different tobacco products. In this study at least 5-7 cigarettes (smoking times) per day were considered to be regular smoking, occasionally - a few times a week, at parties, in stress situations.

Smoking history refers to the time since one smoke regularly, every day. The first episodic smoking experience for all participants was a few years earlier. The earliest smoking experience was for a female student 1 (at the age of thirteen), others smoked for the first time with friends aged 14-15. 
The first focus group discussion was attended by two female students and two male students with different smoking experiences. Female student 1 started smoking 5-6 years ago, now she smokes regularly. She started smoking cigarettes but now switched to heated tobacco. Female student 2 started smoking 5-6 years ago. She prefers cigarettes but has also tried heated tobacco. She smokes irregularly. Male student 1 has started smoking with e-cigarettes but now switched to heated tobacco, he has also smoked cigarettes. He smokes regularly.

The second focus group discussion was attended by two female high school students and three male high school students. Female high school student 1 initiated smoking two years ago, now she smokes cigarettes regularly. She has tried also rolling tobacco, e-cigarette and hookah. Female high school student 2 initiated smoking two years ago, now she smokes cigarettes irregularly. She has tried also rolling tobacco, e-cigarette and hookah. Male high school student 1 initiated smoking a year ago, now he smokes cigarettes regularly. He has tried also rolling tobacco, e-cigarette and hookah. Male high school student 2 smokes fairly intensely - three packs of cigarettes a week, he initiated smoking a year ago. He has tried also e-cigarette and hookah. Male high school student 3 had quit smoking two weeks ago, previously smoked two packs of cigarettes a week. He initiated smoking more than year ago. He has tried also e-cigarettes, heated tobacco, hookah, pipe tobacco, cigars.

Analysis of smoking experience and habits shows that almost all participants in the discussion started smoking a few years after their first "try". Most high school students start smoking regularly at the age of 16. The high school students and students alike have similar experiences with smoking initiation - social motivation predominates. First-time smoking experience is most often among friends. Female high school student 2 told: "From the beginning, of course, it all started so jokey. There with friends to try and so. For half a year now, I have been smoking alone, not just with my friends." Male high school student 3 told: "I had a childhood friend, and with him I started smoking. At first it just seemed attractive as such, and also... it may sound ridiculous, but also masculine in some ways. And I started communicating with him somehow, then every now and then one cigarette. "Male student 1 told: "...at the age of 14 I met my friend, a little older than me. I was such a very right kid (smiles) ... Then I probably tried to do everything I hadn't done before and started smoking. Yes, but it was only one summer when we spent time together, then I smoked, but then it just continued. Well, after a while because classmates smoked a lot and, well, that was how it was - to go to meet somewhere after school or before school and smoke and do something." These experience stories show that smoking during adolescence is often a way to fit in with peers, to be like others, to assert their masculinity, their adult status. Smoking is still perceived by some young people as "stylish, cool".

There were not many people who developed an overwhelming smoking addiction. Most participants of the discussion do not yet smoke very intensively. Only two high school students mentioned that they smoke 2-3 packs of cigarettes a day. Male high school student 2 told: "Well, the body's need for cigarettes is beginning to emerge. I would say that the first year of smoking was so, if I did not want to, then I could quite easily not smoke. Then it really was more of a ritual function." For others, smoking is more a social activity or one of the elements of maintaining a relationship.

Generally speaking, so-called social smoking is prevalent among young people, when the smoker himself/ herself feels in control of the situation and does not depend on smoking, does not think that it is necessary to quit the habit. The study on social smoking concludes that social smokers expect to quit smoking at some point or in the future when their social status and environment change, such as when they finish school, when there is no social tension (Debevec, Daimond, 2012). In practice, this most often turns out to be a switch to regular smoking. Female high school student 2 told: "I was thinking of quitting sometime, and in the near future, but not there at age of 30, of course. I don't really think about it until I finish school because I have stress. I'm the kind of person who can't just relax in some way, and it's one of those ... It's such an important part of my day. Going to school is pretty hard, so I don't want to bother myself with dropping out, because it is such a difficult process. I want to quit just because it is unhealthy and I want it as fast as I possibly can. Somewhere up to 22 or 21, because the lungs are still there. They are still developing, so they can clean themselves up a little bit."

Starting an independent life after leaving parent's home can lead to regular smoking. Male student 2 told: "I have been smoking since the age of 16. I also tried it for the first time at the age of 16. After the first cigarette I had not smoked for another half a year, and then I bought the first pack of cigarettes for Christmas party, then I smoked them, then half a year very rarely. I smoke once a month, and then for 
the first time in six months I for the first time moved to Riga. I lived in Riga in the summer, then I started smoking regularly. That is ... seven or eight cigarettes a day, and now I smoke more, 10 cigarettes a day."

Very often young people have a psychological motivation to smoke. Smoking is often seen by young people as a way to relieve stress, relax and also make contacts - overcoming insecurity by starting communication with strangers such as future co-workers. Male high school student 3 told: “... It culminated in the moment I started working somewhere, because it was a chance to get to know my colleagues faster, and also easier to deal with work stress. Sometimes something complicated that tends to flip over my nerves."

Analysis of relations with others in relation to smoking shows that the attitude towards smoking has always been ambivalent in society. Although smoking has long been considered harmful and it is restricted in public places, smoking is widespread. In families, the attitude to teenagers and adolescents smoking is generally negative, even if the parents themselves smoke. Male student 2 told: “...I have pressure from my mom. Mom has those ironic jokes about smoking in general. She does it herself, she knows she is doing bad things, then she condemns me too. Dad's really like ... He defines it as my free choice".

The attitude of those around them to smoking is more of a concern to high school students. What teachers and classmates think of smokers? Not all high school students smoke. Often non-smoking classmates are intolerant to smokers. Female high school student 1 told: "I'm the only smoker in the class. Some of my classmates have such a negative attitude towards it."

The public does not condemn adolescent smoking. This is evidenced by the stories of the participants of the discussion about how they purchased cigarettes when they were younger than the legal age to buy cigarettes. Female student 1 told: "I live in a very favourable area - there are a lot of small shops with friendly salespeople who are not interested in how young you are and if there is still a girlfriend who looks older... Sold almost always."

High school students, including non-working students, do not always have enough money to buy cigarettes. Then they may also buy cigarettes for lunch money. Female high school student 1 told: "Sometimes you might regret that some of your parent's money goes into cigarettes for something they would definitely not be happy with."

Analysis of the part of the discussion related to smoking restriction show that even smokers themselves, including high school students and students, have no illusions that smoking can be combined with a healthy lifestyle. Male high school student 2 told: "However, you realize that this [smoking] is nothing really good, and also in some way feeling when you smoke... [is not good]. In principle, I have found that I feel best when I do not smoke, but there is some need for those cigarettes..."

However, these thoughts are typical manifestations of social smoking. The phenomenon of "social smoking" emerged in the past decade as an important area of research, largely due to its high prevalence in young adults (Villanti et al., 2017).Female high school student 2 told: "About the future, then maybe if the thought goes so far as to quit, then I don't smoke every day, then I know for sure, even if I don't smoke every day, I will definitely when there will be some celebration, when I will drink something out of the ordinary, then I'll smoke. I don't see myself giving up completely every day." Most participants in the discussion are typical social smokers who intend to quit smoking for some uncertain future, while retaining the opportunity to smoke in various situations - at parties, in the company of friends, when using alcohol, and so on.

A high school student who has been abstaining from smoking for two weeks believes that there are many conditions in the urban environment that encourage smoking. Male high school student 3 told: "You don't have that environment around you at home... you can't smell that smoke. ...in the city where you feel them to some extent. Accordingly, you do not look specifically at people who smoke, but somehow your subconscious catches that they have cigarettes in their hands, and that also drives you to the point that you need to smoke.

The concluding part of the discussion focused on the awareness of young people about alternative tobacco products (e-cigarettes, heated tobacco). Almost all participants of the discussion have tried a wide range of tobacco products and smoking devices, are aware of the prices and options available to purchase these products. This confirms the findings of research carried out abroad that young people are well-informed about market news and want to try those (Cooper et al., 2017). These studies conclude that while young people are curious, dynamic and therefore inclined to try new tobacco products, most 
cigarettes and roll-your-own tobacco are preferred in most cases. The information gathered in the discussions generally confirms these findings.

E-cigarettes have been tried by almost everyone in the discussion, but none are currently being used. Only one participant in the discussion smokes an e-cigarette when meeting old school-time friends who do not live in Riga. However, he is also critical of them. Male student 1 told: "I smoke even better electronic cigarettes because they are tastier, but I noticed that electronic cigarettes can be smoked a lot because, for example, a [traditional] cigarette or IQOS has a certain amount of smoke that you can pull up to the next time, but you can smoke the electronic cigarette virtually non-stop. "The views expressed in the focus group support the findings of other studies that those using e-cigarettes more frequently and those with friends using e-cigarettes perceived e-cigarette use as having a positive social effect (Wallace, Roche, 2018).

The question of whether or not electronic cigarettes encourage young people to smoke is very critical. Male high school student 3 told: "For example, I started [smoking] when those e-cigarettes were not yet popular. I don't know if I'll be able to judge it. Maybe there are young people who are just starting out with e-cigarettes, but at least that's how our generation starts with cigarettes, then try e-cigarettes and then come back to cigarettes anyway." Female high school student 1 told: "The thing about electronic cigarettes was that it was popular for a while. I have never smoked them after 18, but it was stylish at a time when they were still available without documentation and when you are not 18."

Traditional cigarettes are more accessible - they can be stolen from parents, etc., but e-cigarettes must be bought. Male student 1 told: "It doesn't seem to be like that, because for such very young people, if they want to smoke an electronic cigarette, they have to buy it. They're not that cheap, but I could buy a cigarette when I was a kid. It was possible to steal from parents, to settle for a few lats, euros and buy it that way. Electronic cigarette, it is instantly an investment. This way, cigarettes... are easier to get started with because they are easier to access." To sum up, participants in the discussion conclude that, in their view, electronic cigarettes are beginning to "go out of fashion" because they are not comfortable to use, and it is difficult to regulate the amount of smoking, though attractive in many tastes.

Heated tobacco and devices for its use are becoming increasingly popular. Almost everyone in the discussion had tried it, two students switched to using it after a classmate gave it a try. However, the use of heated tobacco devices by young people seems to be uncomfortable compared to traditional cigarettes. Female student2 told: "More and more heated tobacco devices are used in my circle of friends because they really say they almost no longer smoke because these devices need to be recharged, then they also needs to be cleaned. You always have a pack of cigarettes, and those cigarettes are always available."

Although young people are well-informed about new developments in the tobacco market, they want to try them, but in most cases traditional cigarettes are preferred. According to participants of the discussion, young people most often start smoking with traditional cigarettes. This is the experience of the participants of the discussion as well as their observations among peers. Both heated tobacco devices and e-cigarettes are more difficult to access just to try smoking, and expensive devices have to be purchased at specialized outlets.

\section{Conclusions}

Smoking in adolescence is often a way to fit into the peer environment, to be like the rest, to prove your masculinity, the status of an adult person.

A lot of young people consider smoking as "cool".

Young people are predominantly so-called social smoking, when the smoker himself feels that he is in control of the situation and does not depend on smoking, does not think it would be necessary to give up this habit. Social smoking is regarded as one of the elements in starting and maintaining relationships.

Young people often have psychological motivation to smoke. Smoking is often seen by young people as a way to relieve stress and relax. 
While some of the participants in the discussion said that they were not affected by advertising that points to the negative health effects of smoking, they do not speak about the motivation to quit smoking, they argued with the health damage to smoking.

Parents against teenagers smoking are most often negatively treated even when they smoke, but young people do not always consider their parents' opinions.

Youngsters are generally tolerant of smokers - young people are friends with both smokers and non-smokers.

While selling tobacco products to minors is forbidden, small shop assistants sell and "helpful" adults help young people buy these products them.

Although youth funds are limited, the preferred brand for good product quality is preferred for the purchase of cigarettes.

While young people are well aware of the news on the tobacco market and they want to try it out, but in most cases traditional cigarettes are preferred.

According to the participants of the discussion, electronic cigarettes start to "go out of fashion" because they are not comfortable to use, it is difficult to regulate the amount of smoking, although it seems attractive in many and different flavours.

Both the experience of the participants in the discussion and their observations in the peer show that young people most often start smoking with traditional cigarettes. To simply try smoking, both tobacco heating devices and e-cigarettes are more difficult to access, and you need to purchase a high-end device at special outlets.

Although many participants said that tobacco heating devices are stylish and have a number of advantages (can be used indoors, have no unpleasant odours, some discussion participants considered it healthier compared to traditional smoking, etc.), everyone admitted that they should get used to it.

According to the discussion participants, tobacco heating devices are too expensive for teenagers to start smoking with this device.

\section{Bibliography}

1. Bevan I. (2016). E-cigarettes: Smoking Pleasure Reinvented? The Manu Faces of harm Reduction in France. Contemporary Drug Problems, 43(3), 228-241. doi: 10.1177/0091450916657348

2. Cooper M., Loukas A., Harrell M.B., Perry C.L. (2017). College students' perceptions of risk and addictiveness of e-cigarettes and cigarettes. Journal of American College Health, 65(2), 103-111. doi: 10.1080/07448481.2016.1254638

3. Debevec K., Daimond D.W. (2012). Social smokers: Smoking motivations, behavior, vulnerability, and responses to antismoking advertising. Journal of Consumer Behaviour, 11(3), 207-216. doi: 10.1002/cb.1373

4. Egbe C.O., Parry C.DH., Myers B. (2019). Electronic cigarettes: the solution or yet another phase of the tobacco epidemic? South African Journal Psychology, 49(2) 199-205. doi: $10.1177 / 0081246318794828$

5. Fitz C.C., Kaufman A., Moore Ph.J. (2015). Lay theories of smoking and young adult nonsmokers' and smokers' smoking expectations. Journal of Health Psychol, 20(4) 438-445. doi: 10.1177/1359105313502694

6. Johnson A.L., Villanti A.C., Williams V., Rath J.M., Vallone D.M., Abrams D.B., Hedeker D., Mermelstein R.J. (2019). Smoking Trajectory Classes and Impact of Social Smoking Identity in Two Cohorts of U.S. Young Adults. Emerging Adulthood, 7(4) 1-12. doi: $10.1177 / 2167696818763949$

7. Kokarēviča A. (2015.) The Economic Burden of Tobacco use and the Life Quality among the Latvian Working Age Population. In V. Dislere (Ed.), The Proceedings of the International Scientific Conference Rural Environment. Education. Personality (REEP), 8. Jelgava: LLU, 222-229. Retrieved from https://llufb.llu.lv/conference/REEP/2015/Latvia-Univ-Agricult-REEP2015proceedings-222-229.pdf 
8. Lenk K.M., J. Erickson D.J., Forster J.L. (2018). Trajectories of Cigarette Smoking From Teens to Young Adulthood: 2000 to 2013. American Journal of Health Promotion, 32(5) 1214-1220. doi: 10.1177/0890117117696358

9. Regular e-cigarette use remains low among young people in Britain. (2019). Public Health England. Retrieved from https://www.gov.uk/government/news/regular-e-cigarette-use-remainslow-among-young-people-in-britain

10. Ruokolainen O., Ollila H., Karjalainen K. (2017). Determinants of electronic cigarette use among Finnish adults: Results from a population-based survey. Nordic Studies on Alcohol and Drugs, 34(6), 471-480. doi: 10.1177/1455072517736618

11. Gavare I., Lepiksone J. (Eds.). (2017). Smēkēěšanas izplatība un sekas Latvijā 2016. gadā [Prevalence and consequences of smoking in Latvia in 2016]. (5 ${ }^{\text {th }}$ ed.). Rìga: Slimību profilakses un kontroles centrs. Retrieved from https://www.spkc.gov.lv/upload/Zinojumu_faili/sm\%C4\%93\%C4\%B7\%C4\%93\%C5\%A1anas_i zplat\%C4\%ABba_un_sekas_latvij\%C4\%81_2016._gad\%C4\%81.pdf (in Latvian)

12. Villanti A.C., Johnson A.L., Rath J.M., Williams V., Vallone D.M., Abrams D.B., Hedeker D., Mermelstein R.J. (2017). Identifying "social smoking" U.S. young adults using an empiricallydriven approach. Addictive Behaviors, 70, 83-89 doi: 10.1016/j.addbeh.2017.02.004

13. Wallace L.N., Roche M.J. (2018). Vaping in Context: Links Among E-cigarette Use, Social Status, and Peer Influence for College Students. Journal of Drug Education: Substance Abuse Research and Prevention, 48(1-2), 36-53, doi: 10.1177/0047237918807706 